\title{
Influence of cardiopulmonary bypass on water balance hormones in children
}

\author{
M Burch, L Lum, M Elliott, N Carter, D Slater, A Smith, A Ationu
}

\begin{abstract}
Objective-To determine the changes in the endocrine mechanisms of fluid balance after cardiopulmonary bypass in children.

Design-Prospective study; analysis of numbered plasma samples performed blind with respect to clinical data.

Setting-Regional paediatric cardiothoracic unit.

Patients-Nine patients, median age 4, range 2 to 9 years, five males. Patients under the age of 1 year were excluded because of the frequent blood sampling involved.
\end{abstract}

Main outcome measures-Plasma concentrations of atrial natriuretic peptide (ANP), arginine vasopressin, plasma renin activity, aldosterone, noradrenaline and adrenaline, and urinary concentrations of cyclic guanosine monophosphate (cGMP) as measured by radioimmunoassay.

Results-After 30 minutes of cardiopulmonary bypass plasma atrial natriuretic peptide (ANP) decreased from (mean (SEM)) 151 (71) $\mathrm{pg} / \mathrm{ml}$ to 52 (44) $\mathrm{pg} / \mathrm{ml}$ (NS), and urinary production of its second messenger cyclic guanosine monophosphate (cGMP) decreased from 1286 (600) $\mathrm{pmol} / \mathrm{ml}$ to 151 (414) $\mathrm{pmol}$ (p $<\mathbf{0 . 0 5}$ ). Other plasma concentrations of hormones studied did not change significantly although arginine vasopressin, adrenaline, and noradrenaline increased whereas aldosterone and plasma renin activity decreased. After cardiopulmonary bypass stopped there was an immediate and significant rise in plasma ANP, but within the next 24 hours plasma ANP declined significantly (p < $0.05)$, decreasing from 294 (49) $\mathrm{pg} / \mathrm{ml}$ to show the differing pattern of release of water balance hormones invoked by cardiopulmonary bypass. The central role of ANP is shown by its strong correlation with urinary output and its similarly strong relation to fluid balance.

(Br Heart J 1992;68:309-12)

Cardiopulmonary bypass results in complex disturbances of homoeostatic mechanisms including complement activation and consumption, ${ }^{1}$ prostaglandin production, ${ }^{2}$ and secretion of vasopressin and catecholamines. ${ }^{3}$ Furthermore, the metabolic response to cardiopulmonary bypass is more severe in children than in adults. ${ }^{4-6}$ Atrial natriuretic peptide (ANP) is a recently discovered hormone secreted primarily by atrial myocytes in response to local wall stretch and seems to be important in fluid homeostasis ${ }^{7}$; the physiological mechanisms for its release may be exaggerated in childhood. ${ }^{8}$ Recent studies have examined the effect of cardiopulmonary bypass on ANP in adults, ${ }^{9-11}$ but no previous studies have documented the effect of cardiopulmonary bypass on ANP in children. We have therefore studied nine children undergoing bypass and measured plasma concentrations of ANP. Also, we have measured other water balance hormones to provide a complete assessment of the effect of cardiopulmonary bypass on the homeostatic mechansism regulating water balance as this has not been previously undertaken in either adults or children.

Patients and methods

CHARACTERISTICS OF PATIENTS

The parents of all the children involved in this study gave informed consent. The hospital ethics committee gave ethical approval.

We investigated nine patients undergoing elective cardiac surgery. Their median age was 4 (range 2 to 9 ) years and five were males. The surgery undertaken was: repair of atrial septal defect (three patients), repair of tetralogy of Fallot (two), repair of pulmonary atresia with ventricular septal defect with a right ventricular to pulmonary artery homograft (two), and total cavopulmonary connection (two).

\section{ANAESTHETICS}

We used a standard technique. Anaesthesia was induced with cyclopropane and oxygen, suxamethonium ( $1 \mathrm{mg} / \mathrm{kg} / \mathrm{IV}$ ), and pancuronium bromide $(0 \cdot 1 \mathrm{mg} / \mathrm{kg} / \mathrm{IV})$ and maintained with 64 (29) $\mathrm{pg} / \mathrm{ml}$ at 22 hours. In the postoperative period there was a significant correlation between plasma ANP and both mean fluid balance $(r=0.96, p<$ $0.001)$ and mean urine output $(r=0.97$, p $<0.001)$. Plasma aldosterone peaked $(p<0.05)$ at 22 hours after operation, and argine vasopressin peaked $(p<0.05)$ at two hours and then declined $(p<0.05)$ to a trough at 24 hours. Plasma renin activity, adrenaline, noradrenaline, and urinary cGMP concentrations, and mean central venous pressure did not change significantly in the postoperative period.

Conclusion-The changes documented

Hospital for Sick
Children, Great
Ormond Street,
London
M Burch
L Lum
M Elliott
St George's Hospital
Medical School,
London
N Carter
D Slater
A Smith
A Ationu
Correspondence to
Dr M Burch, Department of
Cardiology, Hospital for Sick
Children, Great Ormond
Street, London WC1N 3JH.
Accepted for publication
12 March 1992


nitrous oxide and oxygen with intermittent pancuronium, fentanyl, or morphine.

\section{PERFUSION AND BYPASS}

A non-pulsatile roller occlusive pump maintained perfusion flow rates at $2.41 / \mathrm{m}^{2} / \mathrm{min}$ except transiently.

We used a hollow fibre membrane oxygenator with integral heat exchanger and venoarterial core cooling; cardioplegia was achieved with $\mathrm{St}$ Thomas's No 2 solution. The pump prime had a volume of $1100-1600 \mathrm{ml}$ and the crystalloid component consisted of plasmalyte A. Stored blood containing citrate, phosphate, and dextrose was added in a volume calculated (from a standard nomogram relating surface area to prime volume) to a packed cell volume of $30 \%$ on bypass; $2500 \mathrm{U}$ of heparin was added to each unit of blood and $1600 \mathrm{U}$ to each $500 \mathrm{ml}$ of crystalloid; $8.4 \%$ sodium bicarbonate was added to provide a $\mathrm{pH}$ between $7 \cdot 3$ and $7 \cdot 4$.

As standard practice in our unit a Gambro FH 77 ultra filter with an effective membrane area of $1.4 \mathrm{~m}^{2}$ was inserted between the arterial line of the bypass circuit and the cardiotomy reservoir. The system was topped up with plasmalyte $A$ as the filtrate was formed until $1400 \mathrm{ml}$ of filtrate had been discarded. This volume has been shown to produce a satisfactory reduction in the metabolic load of the pump priming fluid. Perioperative fluids consisted of plasmalyte A, plasma protein fraction, fresh frozen plasma, and blood as indicated by the clinical condition of the patient. On transfer to the intensive care unit $5 \%$ glucose in water was infused at $20 \mathrm{ml} / \mathrm{m}^{2} / \mathrm{hr}$. Potassium chloride was added to maintain plasma potassium concentrations between 4.0 and $5.0 \mathrm{mmol} / 1$. Blood or plasma protein fraction were used for volume replacement to maintain a packed cell volume $>35 \%$.

BLOOD SAMPLING

Blood samples were taken from indwelling arterial cannulae after induction of anaesthesia. Previous studies have shown that the metabolic disturbances are largely complete by six hours, ${ }^{1-3}$ but we extended the sampling period to include the first 24 hours after operation.

Samples were taken after sternotomy, at the start of bypass, every 15 minutes during bypass, and at the end of bypass. Subsequent samples were taken at two, six, 12, 16, 22, and 24 hours after the end of bypass. Blood was collected in tubes containing ethylenediaminetetracetate (EDTA), centrifuged, and plasma was removed and frozen at $-70^{\circ} \mathrm{C}$. As larger volumes of plasma were needed for analysis of adrenaline and noradrenaline postoperative sampling was limited to six, and 24 hours. Also, urine for cyclic guanosine monophosphate (cGMP) analysis was collected less often.

Urine output and fluid balance were expressed as $\mathrm{ml} / \mathrm{kg} / \mathrm{hr}$, and were measured for the hour before plasma sampling, when no diuretic was given. The fluid balance represented net balance of crystalloid and colloid losses including that from chest drains, but insensible losses were not included. Mean values of urinary output and fluid balance were calculated for each sampling period.

Fluids were restricted to $50 \mathrm{ml} / \mathrm{kg}$ of crystalloid/24 hr for all patients, although colloid was given as required.

\section{RADIOIMMUNOASSAY (RIA) PROCEDURES}

Plasma atrial natriuretic peptide (ANP) and arginine vasopressin (AVP) were initially extracted in $\mathrm{C}_{8}$ reversed phase columns (Analytichem International), and their concentrations were then measured by specific RIA as we described for $\mathrm{ANP}^{8}$ and AVP. ${ }^{12}$ Plasma aldosterone was assayed with a commercially available RIA kit according to the manufacturers' instructions (Biogenesis Ltd). The plasma renin activities (PRA) were determined by the method supplied by the Regional Chemical Pathology Unit, St Mary's Hospital, Paddington, London. Urinary cGMP was measured directly in urine by RIA with a commercial kit (NEN Research Products, Du Pont UK Ltd).

HIGH PERFORMANCE LIQUID CHROMATOGRAPHY (HPLC)

Plasma adrenaline and noradrenaline concentrations were measured by HPLC with electrochemical detection after initial extraction of plasma on alumina columns (Laboratory Impex). The system was a $114 \mathrm{M}$ solvent delivery module with an injection valve fitted to a $50 \mu \mathrm{l}$ sample loop with a stainless steel analytical column $(25 \mathrm{~cm} \times 4.6 \mathrm{~mm})$ (Beckman), carrying a $5 \mathrm{~cm} \times 4.6 \mathrm{~mm}$ internal diameter guard column packed with pellicular $\mathrm{C}_{18}$ ODS (Whatman).

The electrochemical detector was an ESA Coulochem model. The mobile phase contained $40 \mathrm{mM}$ citric acid, $80 \mathrm{mM}$ sodium acetate, $60 \mathrm{mM}$ sodium hydroxide, $370 \mathrm{mg} / 1$ EDTA, $280 \mathrm{mg} / 1$ heptane sulphonate (ion pair reagent), and $10 \%$ methanol as organic modifier. Standard adrenaline and noradrenaline $(500 \mathrm{pg} / 50 \mu \mathrm{l})$ and extracted plasma $(50 \mu \mathrm{l})$ containing internal standard were injected into the HPLC system.

\section{STATISTICAL ANALYSIS}

Data are presented as mean (SEM) where appropriate and correlations were obtained by

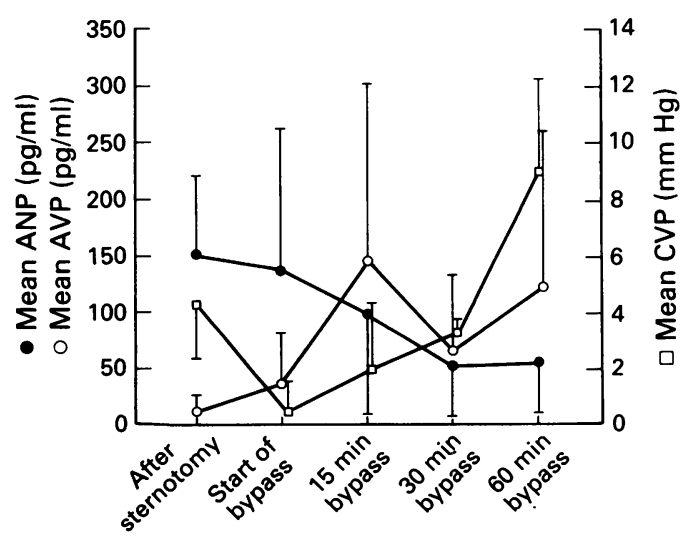

Figure 1 Changes in mean values of plasma ANP, plasma arginine vasopressin $(A V P)$, and central venous pressure (CVP) against time during bypass. 
Figure 2 Changes in mean values of plasma renin activity $(P R A)$ and aldosterone, adrenaline, noradrenaline, and urinary $c G M P$ concentrations with time during bypass.

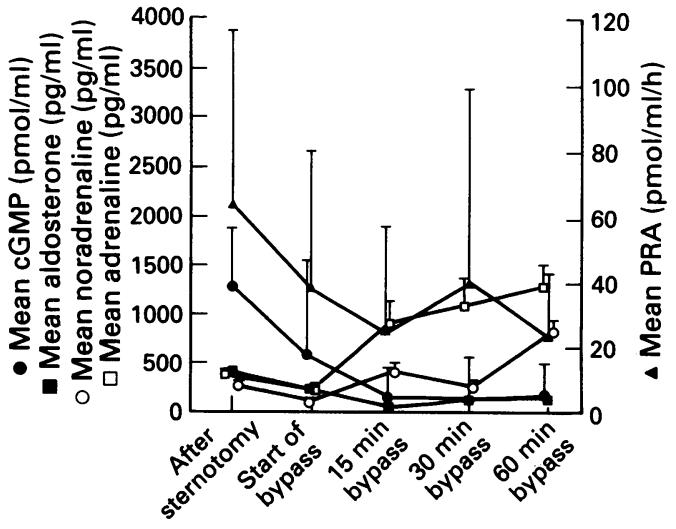

the least squares method. A p value of $<0.05$ was regarded as statistically significant.

\section{Results}

CARDIOPULMONARY BYPASS

Figures 1 and 2 show changes in mean plasma concentrations of ANP, arginine vasopressin, aldosterone, adrenaline, and noradrenaline, and plasma renin activity. Mean concentrations of urinary cGMP are also shown. Results are given up to one hour of bypass although only two patients continued to require bypass for that period. Plasma ANP decreased during bypass and increased significantly $(p<0.05$; fig 3) when bypass stopped. Urinary cGMP decreased significantly $(p<0.05)$ during bypass, reflecting the changes in ANP. Central venous pressure declined and then increased as atrial emptying and filling occurred. Plasma arginine vasopressin, adrenaline, and noradrenaline increased during bypass where aldosterone concentration and plasma renin activity decreased; none of these changes reached statistical significance.

\section{POSTOPERATIVE PERIOD}

Figures 3 and 4 show changes at the end of bypass and during the subsequent 24 hours in the values already discussed. The significant increase in plasma ANP and urinary cGMP after the end of bypass lagged behind the increase in mean central venous pressure. Aldosterone concentration and plasma renin activity increased and arginine vasopressin decreased after bypass but these changes were not significant. Over the next 24 hours ANP concentration declined significantly ( $\mathrm{p}<0.05$ ), to a trough at 22 hours, then increased at 24 hours.

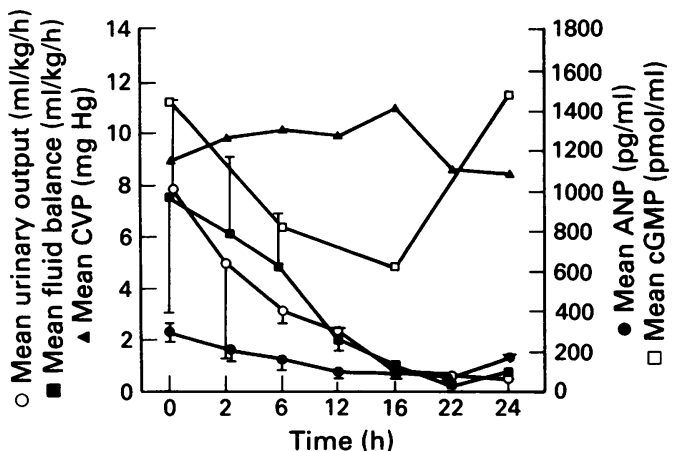

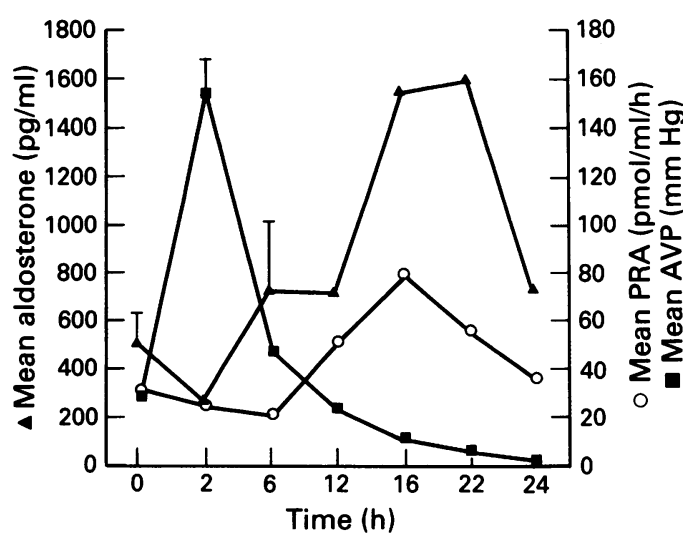

Figure 4 Changes in means for ANP concentration mean cumulative fluid balance, mean urinary output, central venous pressure (CVP), and urinary cGMP concentration with time after operation.

The changes in plasma ANP correlated significantly with mean fluid balance $(r=0.96$, $\mathrm{p}<0.001$; fig 5), but not with mean central venous pressure $(r=0.2, \mathrm{p}=0.6)$. Plasma aldosterone and plasma renin activity increased during the postoperative period. Aldosterone concentrations peaked significantly $(p<0.05)$ at 22 hours in relation to that immediately after bypass and plasma renin activity peaked at 16 hours. Arginine vasopressin concentration significantly decreased $(p<0.05)$ to a trough at 24 hours after peaking two hours after the end of bypass. Mean cGMP also declined in the postoperative period but increased again at 24 hours, although none of these changes were significant. Mean central venous pressure did not change significantly in the postoperative period. Mean adrenaline and noradrenaline were measured less frequently after operation because of the increased volume of plasma required for the assay. The six hour postoperative mean concentration of adrenaline was $1633(208) \mathrm{pg} / \mathrm{ml}$ and noradrenaline 610 (169) $\mathrm{pg} / \mathrm{ml}$, whereas the corresponding 24 hour concentrations were $838(123) \mathrm{pg} / \mathrm{ml}$ and $367(180) \mathrm{pg} / \mathrm{ml}$. After operation only ANP had a significant correlation with urinary output $(r=0.97, \mathrm{p}<0.001$; fig 6$)$. Arginine vasopres$\sin (r=0.6, \mathrm{p}=0.1)$ and cGMP $(r=0.5$, $\mathrm{p}=0.5)$ concentrations had non-significant positive correlations and aldosterone concen-

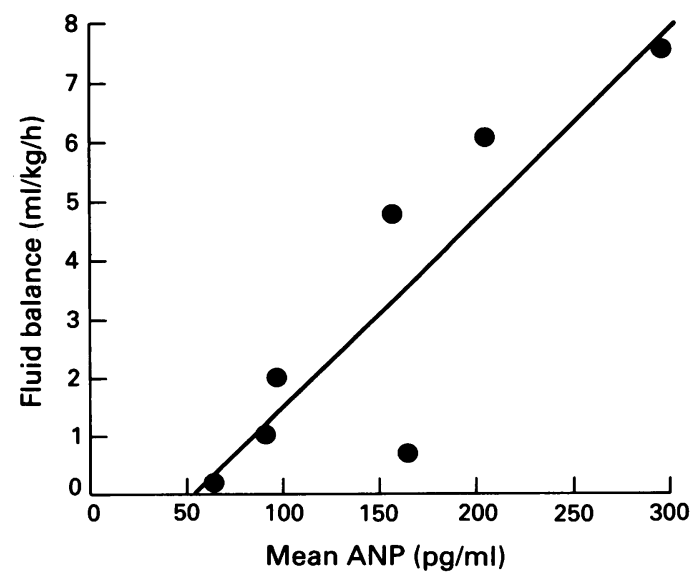

Figure 5 Correlation between mean plasma $A N P$ concentration and mean cumulative fluid balance.
Figure 3 Changes in means for plasma renin activity (PRA) and aldosterone and arginine vasopressin ( $A V P$ ) concentration with time after operation. 


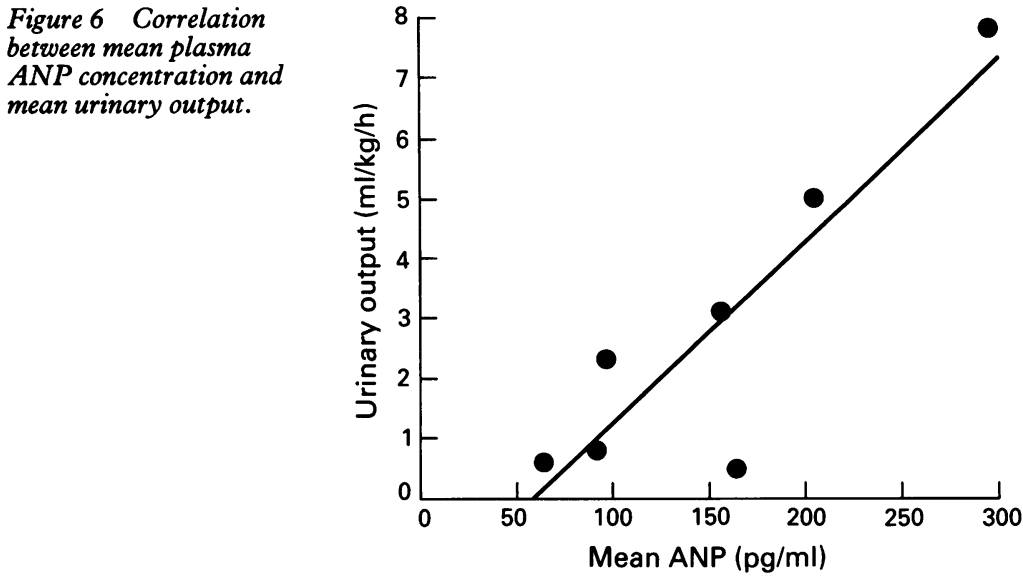

tration $(r=-0.5, \mathrm{p}=0 \cdot 1)$ and plasma renin activity $(r=-0.5, \mathrm{p}=0.2)$ non-significant negative correlations with urinary output. Similarly, there were non-significant negative correlations between ANP and plasma renin activity $(r=-0.6, \mathrm{p}=0.02)$ and aldosterone $(r=-0 \cdot 7, \quad \mathrm{p}=0 \cdot 1)$ and non-significant positive correlations between ANP and cGMP $(r=0.5, \mathrm{p}=0.2)$ and arginine vasopressin $(r=0 \cdot 6, \mathrm{p}=0 \cdot 2)$.

\section{Discussion}

We have shown the different pattern of release of water balance hormones in response to cardiopulmonary bypass in children. Changes in plasma ANP are of interest in that the pattern is consistent and thus predictable. During cardiopulmonary bypass concentrations decreased as the atria were emptied and significantly increased as the heart was filled at the end of bypass, as would be expected if ANP is secreted by atrial myocytes in response to local wall stretch. ${ }^{7}$ Wall stretch is produced by increasing intravascular volume and thus the physiological release mechanism for ANP was shown by the strong correlation between ANP and mean fluid balance in the postoperative period. The narrow band of change in central venous pressure probably explains the far better correlation between ANP and mean fluid balance.

The decline in plasma ANP was shown to be a function of decreasing intravascular volume therefore confirming that the decline in ANP is only rarely related to atypical tamponade. ${ }^{1314}$ Furthermore, the pattern of ANP release seems predictable despite known variations according to the intracardiac repair. ${ }^{15} 16$

The postoperative rise in aldosterone and renin may be explained by the inhibitory effect on their release by ANP, ${ }^{17}$ although it may also be explained by the fluid restriction in the postoperative period. The peaks in arginine vasopressin concentration coincided with declines in ANP. This may be predicted as ANP also inhibits arginine vasopressin release.$^{18}$ Overall, however, arginine vasopressin tended to decrease after operation and had a weak positive correlation with ANP. Changes in urinary cGMP reflected changs in plasma ANP, as would be expected if it is the second messenger for ANP. ${ }^{19}$ As with all other hormones measured the correlation with ANP did not reach statistical significance.

Although positive (arginine vasopressin and cGMP) and negative (plasma renin and aldosterone) relation with urine output were documented none reached statistical significance. The only hormone that had a positive correlation with urinary output was ANP $(r=0.97, \mathrm{p}<0.001)$. This illustrates its known diuretic action. ${ }^{20}$

Our results show a pattern of change in water balance hormones after cardiopulmonary bypass in children and provide a useful framework for therapeutic intervention that with the use of angiotensin converting enzyme inhibitors and possibly intravenous $\mathrm{ANP}^{21}$ is increasingly targeted at the endocrine system.

This work was supported by the British Heart Foundation.

1 Chiu RCJ, Samjon R. Complement (c3, c4) consumption in cardiopulmonary bypass, cardioplegia and protamine cardiopulmonary bypass, cardioplegia and protam

2 Fagmoville ME, Deby-Dupont G, Larbuisson R, et al. Prostaglandin E2, prostacycline and thromboxane changes during nonpulsatile cardiopulmonary bypass in humans. J Thorac Cardiovasc Surg 1986;91:858-66.

3 Hine IP, Wood WG, Mainwaring-Burton RW, et al. The adrenergic response to surgery involving cardiopulmonary bypass as measured by plasma and urinary cate-
cholamine concentrations. Br J Anaesth 1976;48:355-63.

4 Milne EMG, Elliot MJ, Pearson DT, Holden MP, Albert KGMM. The effect on intermediary metabolism of open heart surgery with deep hypothermia and circulating heart surgery with deep hypothermia and circulating arrest in infants of less than $10 \mathrm{~kg}$ bod

5 Baum D, Dillard DH, Porter D. Inhibition of insulin release in infants undergoing deep hypothermic cardiovascular in infants undergoing deep hypothermic

6 Baum D, Dillard DH, Mohri H, Crawford EW. Metabolic aspects of deep surgical hypothermia in infancy. Pediatrics 1968;42:93-105

7 Brenner BM, Ballermann BJ, Gunning ME, Zeidel ML. Diverse biological actions of atrial natriuretic peptide. Physiol Rev 1990;70:665-99.

8 Burch M, Till JA, Rigby ML, et al. Plasma concentration of atrial natriuretic peptide in spontaneous atrioventricular re-entrant tachycardia of childhood. Br Heart J 1990 64:317-20.

9 Dewar ML, Walsh G, Chiu CJ, et al. Atrial natriuretic factor: response to cardiac operation. $J$ Thorac Cardiovasc Surg 1988;96:266-70.

10 Asari H, Kondo H, Ishihara A, Ando K, Marumo F. Extra corporeal circulation influence on plasma atrial natriuretic peptide concentration in cardiac surgery patients. Chest peptide concen

11 Oyama T, Kudo T, Kudo M, et al. Plasma concentration of human atrial natriuretic polypeptide during cardiopulmonary bypass under fentanyl anaesthesia. Agressologie 1986;27:687-9.

12 McIntosh N, Smith A. Serial measurement of arginine vasopressin in the newborn. Arch Dis Child 1985;60 $1031-5$

13 Shore DF, Capuani A, Lincoln C. Atypical tamponade after cardial operation in infants and children. $J$ Thorac Cardiovasc Surg 1982;83:449-52.

14 Burch M, Lincoln C, Carter N, Smith A. Acute sterna opening after cardiac surgery in children: effect on plasma atrial natriuretic peptide. J Cardiovasc Surg 1991;32 246-50.

15 Stewart JM, Seligman KP, Zeballos G, et al. Elevated atria natriuretic peptide after the Fontan procedure. Circulation 1987;76:77-8.

16 Burch M, Shineborne EA, Rigby ML, et al. Plasma atria natriuretic peptide after the Fontan procedure and total

17 Maack T, Marion DN, Camargo MJ, et al. Effects of auriculin on blood pressure, renal function and the reninauriculin on blood pressure, renal function and the renin-

18 Samson WK. Atrial natriuretic factor inhibits dehydration and haemorrhage induced vasopressin release. Neuroendocrinology 1985;40:277-9.

19 Hamlet $\mathrm{P}$, Tremblay J, Pang SC, et al. Effect of native and synthetic atrial natriuretic factor on cyclic GMP. Biochem Biophys Res Commun 1984;123:515-27.

20 Anderson JV, Donckier J, Payne NN, Beacham JD, Bloom $\mathrm{SR}$. Atrial natriuretic peptide: evidence of action as a natriuretic hormone at physiological plasma concentrations in man. Clin Sci 1987;72:305-12.

21 Saito Y, Nakao K, Nishimura A, et al. Clinical application of atrial natriuretic polypeptide in patients with congestive heart failure: beneficial effects on left ventricular function Circulation 1987;76:115-24. 